\title{
Design Analysis of Bevel Gear for Gearmotor Selection in Revolving Platform
}

\author{
Nurudeen A. Rajii', Kasali A. Adedeji ${ }^{1}$, Elkanah 0. Oyetunji ${ }^{1}$, Ayodeji D. Agbelusi ${ }^{2}$ \\ ${ }^{1}$ Mechanical Engineering Department, Lagos State University, Lagos, Nigeria \\ ${ }^{2}$ CFAO Motors, Lagos, Nigeria \\ Email: nurudeen.raji@lasu.edu.ng
}

How to cite this paper: Raji, N.A., Adedeji, K.A., Oyetunji, E.O. and Agbelusi, A.D. (2021) Design Analysis of Bevel Gear for Gearmotor Selection in Revolving Platform. Modern Mechanical Engineering, 11, 1-11. https://doi.org/10.4236/mme.2021.111001

Received: April 4, 2020

Accepted: February 23, 2021

Published: February 26, 2021

Copyright $\odot 2021$ by author(s) and Scientific Research Publishing Inc. This work is licensed under the Creative Commons Attribution International License (CC BY 4.0).

http://creativecommons.org/licenses/by/4.0/

\begin{abstract}
The design of bevel gear for use in the development of revolving rostrum is presented. The pinion gear is designed to rotate at $1400 \mathrm{rpm}$ for the output gear of $23 \mathrm{rpm}$. A suitable gearmotor was selected for the design based on the bevel gear design analysis. The motion is transmitted to the rostrum via a shaft keyed to it with a gib-head key and assembled on the rostrum with a spline connector. The analysis of the bevel mesh shows that maximum deformation of about $26.552 \mathrm{~mm}$ occurs in the pinion due to the loading the pinion tooth. The deformation of the tooth is observed to affect considerable the performance of the system. The transmission efficiency of the mechanism was obtained as $86 \%$ though effective for the operation of the system but could be improved by a more careful material selection for the bevel gear mesh.
\end{abstract}

\section{Keywords}

Rostrum, Bevel Gear, Gearbox, Spline, Shaft, Torque, Key, Mechanism

\section{Introduction}

The design of rostrum had undergone quality development over the years depending on the specific areas of application ranging from award presentation to public address functions and church activities. Different design of the rostrum has evolved in recent time to incorporate conveniences in reaching the targeted audience. The design of rotary rostrum could be a convenient concept of its usage in large halls. Several mechanisms could be used to achieve rotary motion ranging such as pulley systems, gear systems, sprocket and chain, and worm and worm wheel among others. The choice of the bevel gear mesh mechanism for rotary motion of the rostrum is discussed in this article. The choice of the bevel 
gear mesh mechanism is centered on the possibility of reversing the direction of rotation as it is required for rostrum operation and to increase or decrease the speed of rotation. Bevel gears are widely used to transmit motion and power via shafts arranged at angle of $90^{\circ}$ [1]. Its usage is conspicuously found in gearbox.

Bevel gears have teeth cut on conical blanks. The gear pair is used to connect nonparallel intersecting shafts for motor transmission, differential drives, and mechanical instruments. The application of bevel gears could be found in locomotives, railway tracks, power plants, printing press machines among other applications. Bevel gear meshing as a transmission mechanism has been extensively used for the concept of transmitting rotary motion in machines. Spiral bevel gears are used in the design of helicopter power transmission systems [2]. The bevel gears in the helicopter systems were designed to transfer power from the horizontal engines to the vertical rotor shaft. The selection is the ability of the gears to carry high loads and operate at very high rotational speeds. The possibility of realizing large angular movement in mechanism has also given credence to its use in Photo Voltaic tracking system [3]. The likely failure of the mechanism is usually due to dynamic load and wears which causes bending and wear of the gear teeth. Geometric programming technique has been used to optimize the design procedure of the gear mesh for purpose of limiting such effect. A contact stress capacity model could be developed for the straight bevel gear using geometric approximation as presented in [4]. The successful use of the bevel gear mechanism for machine operation relies on the optimum design consideration for the gears contact forces, geometrical gear equivalence, and the contact fatigue analysis. Several authors have dwell on the optimization procedures for the design of bevel gear mechanism and the identification of the possible failures often encountered in bevel gear operations [5] [6] [7] [8] [9]. In the concept of the rostrum, a pair of bevel gears with spherical involutes teeth transfer power and motion over $180^{\circ}$ with line contact.

\section{Materials and Methods}

The design of the revolving rostrum is as shown in Figure 1. The rostrum as designed consists of three assemblies, the structure frame, the transmission system, and the control system.

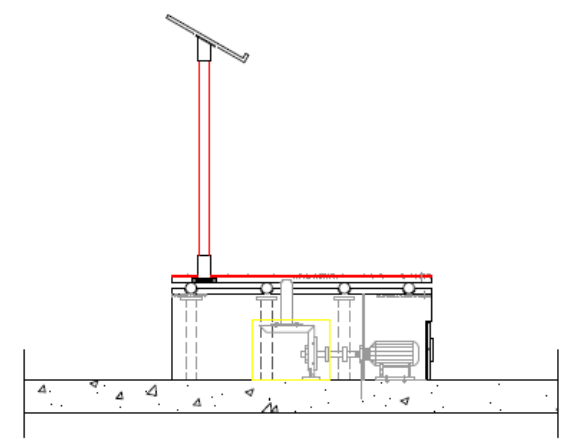

Figure 1. Conceptual scheme for the revolving rostrum. 
The structure frame is made up of the rostrum platform, the gearmotor drive enclosure brazed with angle iron frame. The transmission system composed of a gearmotor with a machined shaft assembled on the motor to support the rotational motion of the rostrum platform. The control system is an electrical system design to allow for $180^{\circ}$ rotation of the entire system. The design for the structure frame and the transmission system is discussed in this paper while the control system design will be discussed in another paper.

\subsection{The Structure Frame Design}

The frame stem is made of hollow steel pipes of $27 \mathrm{~mm}$ and $38 \mathrm{~mm}$ diameter. The two pipes are assembled using the screw knob for purpose of adjustment between $1 \mathrm{~m}$ to $1.3 \mathrm{~m}$. The platform is made of $10 \mathrm{~mm}$ thick steel plate for the top of the gear enclosure. The frame stem is assembled on the platform using a step flange. The gear motor is mounted on a seat plate of $23 \mathrm{~mm} \times 12 \mathrm{~mm}$, supported by two angle plates of 70 by $70 \mathrm{~mm}$ width sizes welded to the cylindrical enclosure. The manufacturing process involve include cutting, grinding, welding and the use of bolt and nuts where necessary for structural rigidity.

\subsection{Transmission System Design}

The transmission system comprises the shaft assembled on the bevel gear mesh of a gearmotor assembly.

Bevel gear mesh design: In this case the straight bevel gear is intended for the design requirement of the gearmotor. The design of the bevel gear here is based on strength and the dynamic load input and output. The bevel gear configuration is as shown in Figure 2.

The thrust force on the gear and speed specification is given in Table 1.

The tangential force perpendicular to the plane of the axes is obtained as in Equation (1)

$$
F_{t}=\frac{F_{o}}{\tan \phi \cos \delta}
$$

$\phi$ and $\delta$ are the gears pressure and reference cone angles respectively.

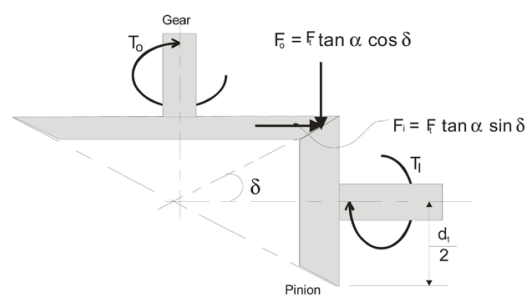

Figure 2. Bevel gear configuration.

Table 1. Design specification.

\begin{tabular}{ccc}
\hline Design load & Fo & $<3000 \mathrm{~N}$ \\
\hline Operating speed range & $\mathrm{n}$ & $20-25 \mathrm{rpm}$ \\
\hline
\end{tabular}


The thrust force on the input pinion and output gear is obtained from Equations (2).

$$
\begin{aligned}
& F_{i}=F_{t} \tan \alpha \sin \delta \\
& F_{o}=F_{t} \tan \alpha \cos \delta
\end{aligned}
$$

The input and the output torque could be obtained as expressed in Equations (3) and (4) [10].

$$
T_{i}=F_{i} R_{i}
$$

The torque load for the input gear is obtained as [4].

$$
\begin{gathered}
T_{i}=\frac{30 P\left(10^{3}\right)}{\pi n_{i}} \\
T_{o}=\kappa G T_{i}
\end{gathered}
$$

The central reference diameter of the output gear in the gear unit of the motor gear should not exceed the range as determined in Equation (5).

$$
d_{m}=200\left(\frac{T_{o}}{F_{t}}\right)
$$

The bending stress in the bevel gear when loaded could be obtained from Equation (6) (AGMA 2003-B97) [11].

$$
\sigma_{F}=\frac{1000 F_{t}}{b} \frac{K_{A} K_{V}}{m_{e t}} \frac{Y_{x} K_{H \beta}}{Y_{\beta} Y_{J}}
$$

where $\sigma_{F}$ is the bending stress, $b$ is the tooth face width, $K_{A}$ is the overload factor, $K_{V}$ is the dynamic factor, $m_{e t}$ is the outer transverse module, $Y_{x}$ is the size factor for bending strength, $K_{H \beta}$ is the load distribution factor, $Y_{\beta}$ lengthwise curvature factor for bending strength, $Y_{\beta}$ geometry factor for bending strength. The selection of the various factors centered on the possibility of the uncertainty in the loading condition of the bevel gear mesh in rostrum operation. These factors could be determined and selected as detail in AGMA 2003-B97 [11]. The pitch-line velocity of the gear is often required for determining the factors and this is obtained as expressed in Equation (7).

$$
v=5.236 \times 10^{-5} d_{1} n_{1}
$$

where $d_{1}$ and $n_{1}$ are the pitch diameter and speed of the pinion in the mesh.

Gearmotor selection: The gearmotor which consists of a gear unit and electric motor is selected for the transmission system. The specification of the gearmotor is obtained from the force analysis of the rostrum function. The gear unit tends to reduce speed and increase the torque that may be required for the operation of the system. The most important parameters in regards to gearmotor are the speed torque and efficiency. The addition of a gear box is intended to limit the speed of the motor's shaft, and increase the motor's ability to output torque. It is intended to evaluate optimum operational speed of the rostrum and then determine the torque required to meet the needed performance. 
The basic size of the gearbox is obtained from the estimation of the output torque considering the anti-reversing specification of the system for sudden brake application in the rostrum desired position during operation. The specification for the gearbox selection process include the consideration for the operation cycle, upper bound input speed and the upper bound torque. The rostrum is designed for output speed range of $20-25 \mathrm{rpm}$ assuming that the rostrum is operating at an extreme duty cycle of 24 hours per day with the rostrum operating under uniform loading shock situation. The safety factor satisfying this consideration is obtained as $\kappa(1.55)$. The output torque is obtained as expressed in Equations (1)-(3).

A wide range of motor sizes and gearbox ratios could achieve the specific output torque and the speed, however conceptually in this case; a pre-engineered gearmotor is selected from the vendor's gearmotor curve. The gearmotor curve combines the performance of the motor and gearbox together by displaying torque and efficiency. The specification of the gearmotor for this design is obtained as tabulated in Table 2.

Output shaft design with keys selections: The output shaft is assembled on the gearmotor output gear as shown in Figure 3. The shaft is machined to accommodate the gear hub diameter of $40 \mathrm{~mm}$ and also at the bearing of the rostrum platform support. The diameter of the shaft could be obtained from Equation (8) as discussed in [12].

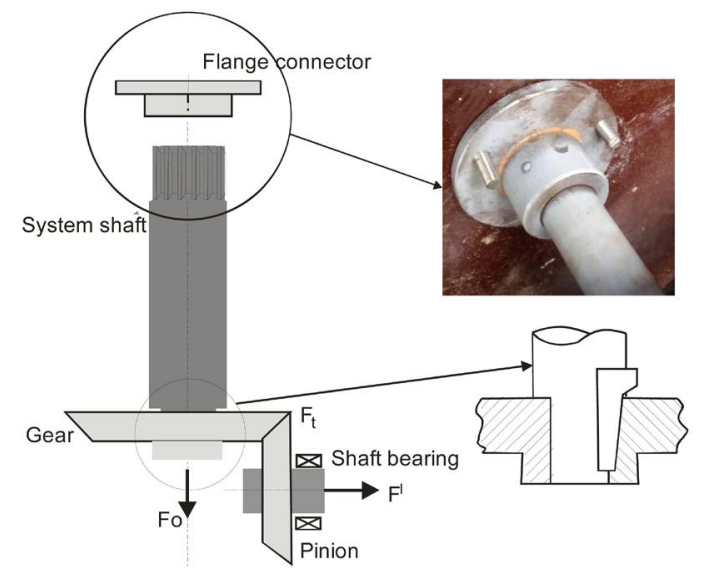

Figure 3. Geometric layout for the shaft.

Table 2. Gearmotor selection.

\begin{tabular}{cc}
\hline Parameter & \\
\hline Motor power & $0.75 \mathrm{~kW}$ \\
Torque & $114 \mathrm{Nm}$ \\
Motor Speed & $1400 \mathrm{rpm}$ \\
Gearmotor speed & $23 \mathrm{rpm}$ \\
Output shaft hub dia. & $40 \mathrm{~mm}$ \\
Efficiency & 0.753 \\
\hline
\end{tabular}




$$
d_{o}^{3}=\frac{16}{\pi \tau_{\text {all }}\left(1-c^{4}\right)} \sqrt{\left(k_{m} M+\frac{\alpha F_{o} d_{o}\left(1+c^{4}\right)}{8}\right)^{2}+\left(k_{t} T\right)^{2}+\left(k_{t} T\right)^{2}}
$$

$\alpha$ is the column action factor which usually arise due to the phenomena of buckling of the shaft due to the axial load on the shaft. The value of $\alpha$ could be obtain as expressed in Equation (9)

$$
\alpha=\frac{1}{1-0.0044 \lambda}
$$

where $\lambda=\frac{L}{r}, L$ is the shaft length and $r$ is the shaft radius, $c=\frac{d_{i}}{d}$.

Where $k_{m}$ and $k_{t}$ are the bending and torsion factors accounts ${ }^{\circ}$ for shock and fatigue. The values of the factors are selected considering suddenly applied load and minor shock condition for the design. $\tau_{\text {all }}$ is the material yield strength, $M$ is the bending moment due to the shaft loading, $T$ is the torsion load on the shaft, $F_{o}$ (Design load) is the axial force on the shaft as obtained for the bevel gear.

The specified parameters are shown in Table 3. The shaft is connected to the gearbox output gear via a gib head key. The key is to avoid failure by crushing and shatter which could result from the mild shock at the start of motion and end of motion during operation of the machine due to jerk and the gib head key of nominal height of $8 \mathrm{~mm}$ and width of $12 \mathrm{~mm}$ with $9 \mathrm{~mm}$ thickness is selected from standard DIN 6887/ISO 2497.

The spline connection is used for connecting the shaft to the flange carrying the rotating platform. The ISO 5480 is used for the connection design with involutes splines on the shaft and flange-hub. The pressure angle for the involutes cut is $30^{\circ}$. The spline design data is as shown in Table 4 .

Table 3. Design constants.

\begin{tabular}{ll}
\hline \multicolumn{3}{c}{ Selected Design Parameters } \\
\hline $\mathrm{kt}$ & 1.55 \\
$\mathrm{~km}$ & 1.25 \\
& $40 \mathrm{MPa}$ \\
\hline
\end{tabular}

Table 4. Spline connection data.

\begin{tabular}{cc}
\hline \multicolumn{1}{c}{ Parameter of spline coupling } \\
\hline Module & 1.55 \\
Pressure angle (degree) & 30 \\
pitch (mm) & 4.87 \\
Number of teeth & 18 \\
Root dia. $(\mathrm{mm})$ & 35.5 \\
Outside dia. $(\mathrm{mm})$ & 39.8 \\
\hline
\end{tabular}


The involutes cut ensure constant torque load, $T$, over the length, $L_{s}$, of the spline. The torque deformation angle $\phi_{\max }$ could be obtained as [13]

$$
\phi_{\max }=\frac{T L_{s}}{2 G I_{p}}
$$

The involutes teeth are designed against deformation at the tooth root [14] as expressed in Equation (11).

$$
\delta_{R}=F_{o} \frac{\cos ^{2} \theta}{W E}\left[\frac{16.67}{\pi}\left(\frac{L_{s}}{\pi}\right)^{2}+2(1-\mu)\left(\frac{L_{s}}{h}\right)+1.534\left(1+\frac{\tan ^{2} \theta}{2.4(1+\mu)}\right)\right]
$$

where $P$ is the applied load and $\theta$ is the angle at which the load is applied to the system.

The stiffness of the tooth could be obtained from the Equation (12) [14].

$$
K_{T}=\frac{F_{o}}{\delta_{R}}
$$

Modeling and analysis: The bevel gear mesh assembly was prepared using the solid-work software and imported to the ANSYS workbench 15.0 for structural and dynamic analysis of the bevel mesh. The model was analyzed for the tooth deformation and bending stress.

\section{Results Discussion}

Figure 4 and Figure 5 show the distribution plots for the ANSYS.

Tooth root deformation: The structural stress analysis on the bevel gear mesh shows that the maximum deformation of the gear mesh is obtained as 26.552 $\mathrm{mm}$.

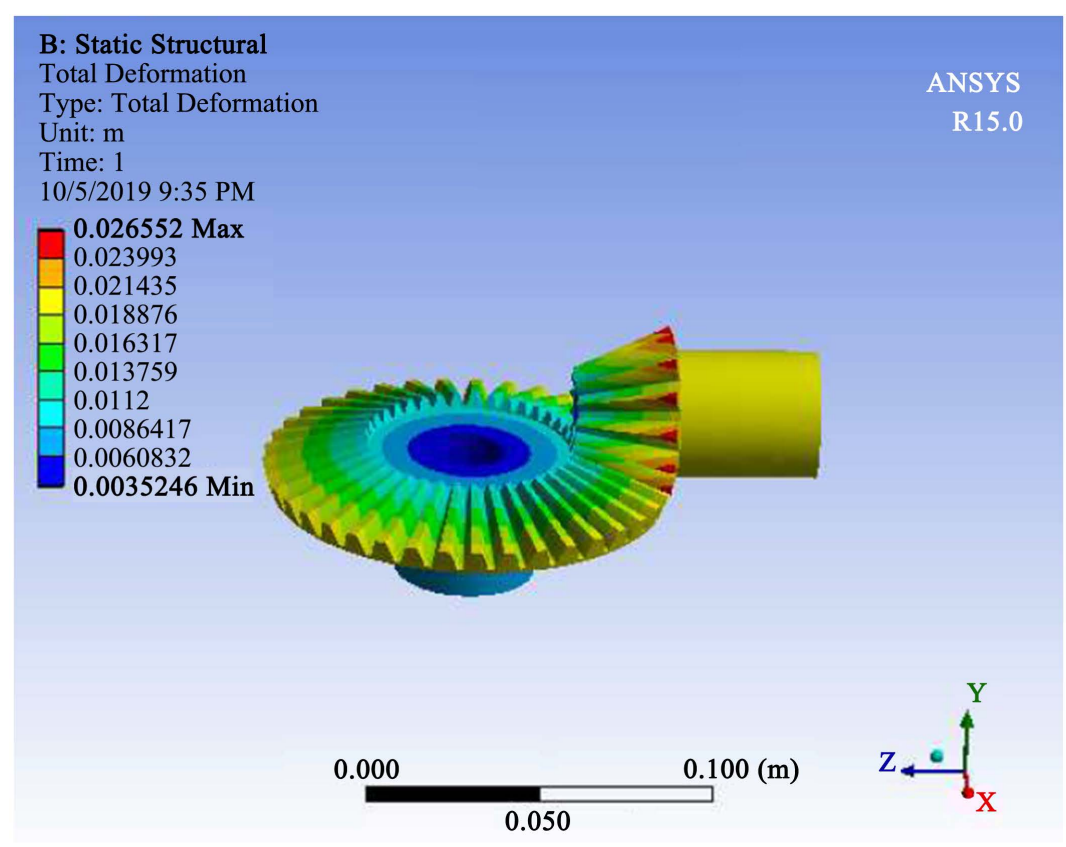

Figure 4. Bevel gear deformation analyses. 


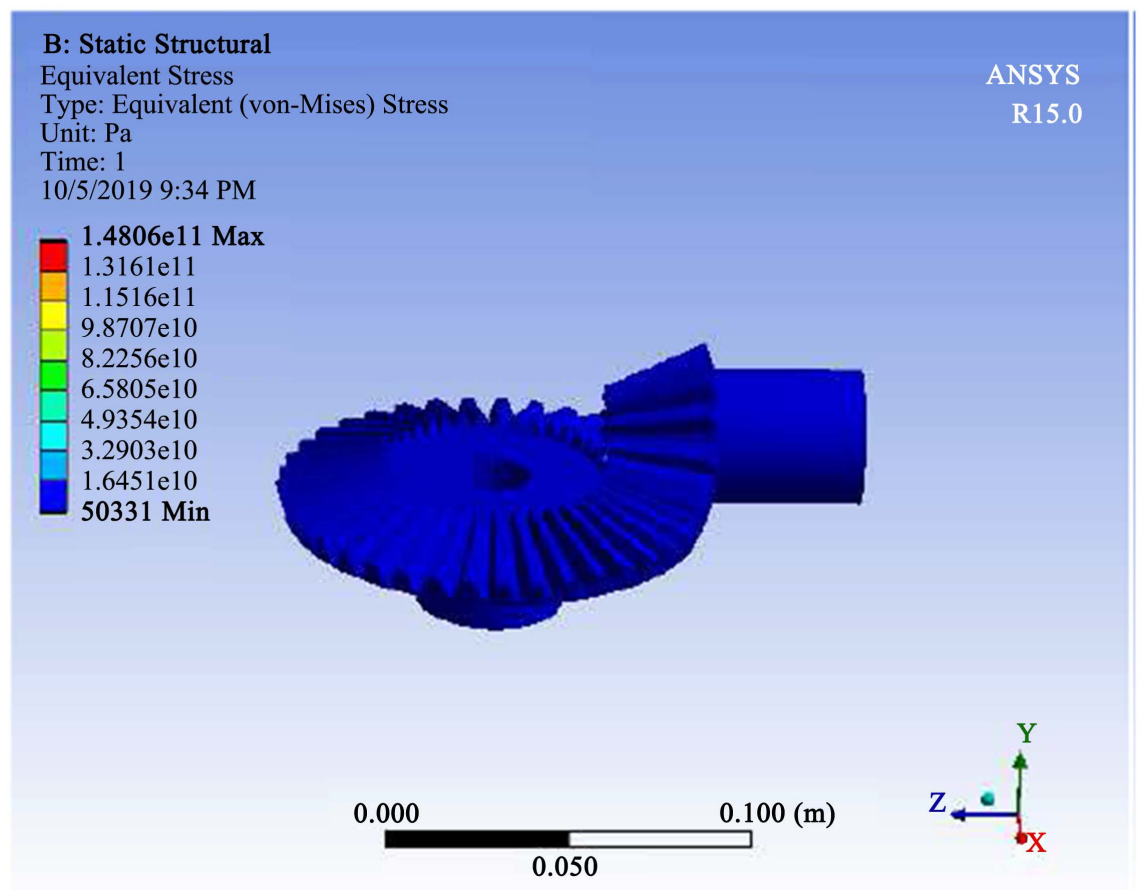

Figure 5. Bevel gear bending stress analyses.

The maximum deformation occurred on the pinion gear as shown in Figure 4. The figure shows the stress distribution resulting into the gear mesh deformation. The deformation at the pinion gear could be responsible for the lower torque transmission to the gear.

Bending stress: The bending stress value at the root of the tooth is as distributed in Figure 5. The maximum bending stress is obtained as $148 \mathrm{GPa}$ which is rather high for such design suggesting the possibility of iteration process for the material selection among several materials that could be available for the design rather than been specific with using mild steel as is selected for the design. It is evident in gear design that the bending stress is often dependent on the gear face width. It is a general study that the maximum bending stress could be reduced by increasing the face width of the gear tooth.

Performance evaluation of the rostrum: The performance of the mechanism for the operation of the rostrum has been examined. The response of the rostrum platform under the turning effect of the bevel gear mechanism was investigated. The technical evaluation of the system was carried out using arbitrarily chosen set of load values between $35-250 \mathrm{~kg}$ to evaluate the system below and above design load.

The result of the motion geometry is as shown in Figure 6. At the start and end of motion the performance of the rostrum suggest that there is likely to be a rate of change of acceleration showing the jerk nature of the system at the start of the motion as a result of change in the direction of motion from the forward to the return motion and vice-versa. The behavior of the mechanism at this instant seems asymptotic even as it becomes zero at the end of the motion which is 


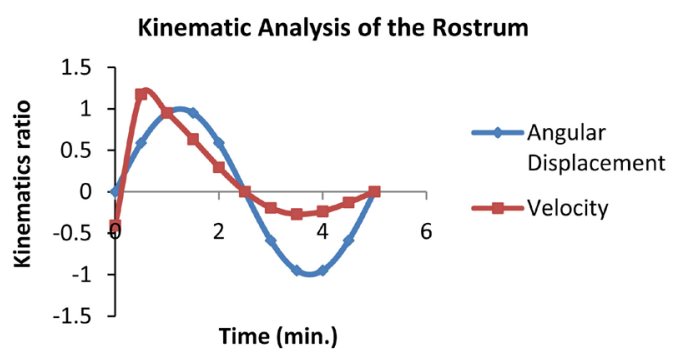

Figure 6. Kinematic analyses for the rostrum motion.

not likely to be except the machine is intended to stop operation at that moment. This effect results in a light vibration of the system and is required to be smoothened for effective performance. Evaluation of the bevel gear efficiency indicated a transmission efficiency of $86 \%$. The lubrication of the mechanism tends to improve the efficiency by $6 \%$. This is could be due to the reduction in the end jerk effect at the start and end of motion during the operation of the system.

\section{Conclusion}

The use of bevel gear mechanism for machine motion synthesis cannot be overemphasized. The construction and development of the revolving rostrum requirements on functionality and availability was demonstrated by the design of the bevel gear mechanism and the selection of appropriate gearmotor based on the gear design. The bevel gear unit, the rostrum frame and the platform were powered by an electric motor of $0.75 \mathrm{~kW}$ with $1400 \mathrm{rpm}$. Performance evaluation of the machine shows that the transmission efficiency of the bevel gear is $86 \%$ for the power requirement. The efficiency tends to improve by $6 \%$ when the mechanism is lubricated.

\section{Acknowledgements}

The authors would like to acknowledge the support from CFAO motors at Lagos, Nigeria for their kind assistance allowing the use of their facility for this research work.

\section{Conflicts of Interest}

The authors declare no conflicts of interest regarding the publication of this paper.

\section{References}

[1] Joshi, H.D. and Kothari, K.D. (2014) Mode and Cause of Failure of a Bevel Gear-A Review. International Journal of Advance Engineering and Research Development (IJAERD), 1, 1-9. https://doi.org/10.21090/IJAERD.01025

[2] Hegne, A.V. and Hegne, P. (2013) Design and Power Transmission of Advanced Light Helicopter. International Journal of Engineering Research and Applications, 3, 219-223.

[3] Moldovean, G., Gavrila, C. and Butuc, B. (2013) Fatigue Stress Calculation of Straight 
Bevel Gears Applied to a Photo-Voltaic Tracking System. Annals of the Oradea University, 1, 205-210. https://doi.org/10.15660/AUOFMTE.2013-1.2813

[4] Osakue, E.E. and Anetor, L. (2018) Design of Straight Bevel Gear for Pitting Resistance. Faculty of Mechanical Engineering Transactions, 46, 194-204. https://doi.org/10.5937/fmet18021940

[5] Siddiqui, N.A., Deen, K.M., Khan, M.Z. and Ahmad, R. (2013) Investigating the Failure of Bevel Gears in an Aircraft Engine. Case Studies in Engineering Failure Analysis, 1, 24-31. https://doi.org/10.1016/j.csefa.2012.12.001

[6] Baudin, S., Remond, D., Antoni, J. and Sauvage, O. (2014) Detection of Rattle Noise with Optical Encoders in Run-Up Conditions. Proceedings of ISMA, 2777-2786.

[7] Feng, Z. and Song, C. (2017) Effects of Geometry Design Parameters on the Static Strength and Dynamics for Spiral Bevel Gear. International Journal of Rotating Machinery, 1-8. https://doi.org/10.1155/2017/6842938

[8] Crivoi, O. and Doroftei, I. (2018) Robotic Wrists Mechanisms with Bevel Internal Gears Having a Small Difference in Numbers of Teeth. The 8th International Conference on Advanced Concepts in Mechanical Engineering IOP Publishing IOP Conference Series: Materials Science and Engineering, 444, 052017. https://doi.org/10.1088/1757-899X/444/5/052017

[9] Acinapura, A., Fragomeni, G., Greco, P.F., Mundo, D., Carbone, G. and Danieli, G. (2019) Design and Prototyping of Miniaturized Straight Bevel Gears for Biomedical Applications. Machines, 38, 1-6. https://doi.org/10.3390/machines7020038

[10] Karaveer, V., Mogrekar, A. and Joseph, T.P.R. (2013) Modeling and Finite Element Analysis of Spur Gear. International Journal of Current Engineering and Technology, 3, 2104-2107.

[11] Budynas, R.G. and Nisbett, J.K. (2011) Mechanical Engineering Design. 9th Edition, McGraw-Hill Publisher, New York, 1109.

[12] Raji, N.A., Adedeji, K.A., Olaleye, J.O. and Adele, F.A. (2019) Design and Fabrication of Tiger Nut Juice Extractor. Journal of Applied Sciences and Environmental Management, 23, 563-568. https://doi.org/10.4314/jasem.v23i3.29

[13] Schäfer, G. and Garzke, M. (2002) Increasing Load Capacity of Splines Due to Design. International Design Conference, Dubrovnik, 14-17 May 2002, 695-700.

[14] Cura, F., Mura, A. and Gravina, M. (2012) Load Distribution in Spline Coupling Teeth with Parallel Offset Misalignment. Proc IMechE Part C: Journal of Mechanical Engineering Science, 1-11. 


\section{Nomenclature}

\begin{tabular}{|c|c|c|}
\hline$b$ & tooth face width & $\mathrm{mm}$ \\
\hline$d_{1}$ & pitch diameter & $\mathrm{mm}$ \\
\hline$d_{m}$ & gear central reference diameter & $\mathrm{mm}$ \\
\hline$E$ & modulus of elasticity & $\mathrm{MPa}$ \\
\hline$F_{i}$ & input gear force & $\mathrm{N}$ \\
\hline$F_{o}$ & ouput gear force & $\mathrm{N}$ \\
\hline$F_{t}$ & tangential gear force & $\mathrm{N}$ \\
\hline$G$ & rigidity modulus & $\mathrm{MPa}$ \\
\hline$K_{A}$ & overload factor & \\
\hline$K_{H \beta}$ & load distribution factor & \\
\hline$K_{T}$ & spline tooth stiffness & $\mathrm{N} / \mathrm{mm}$ \\
\hline$K_{V}$ & dynamic factor & \\
\hline$k_{m}$ & bending stress shock factor & \\
\hline$k_{t}$ & torsion load fatigue factor & \\
\hline$L$ & shaft length & $\mathrm{m}$ \\
\hline$L_{s}$ & length of the spline. & $\mathrm{m}$ \\
\hline$M$ & bending moment & $\mathrm{N} \cdot \mathrm{m}$ \\
\hline$m_{e t}$ & outer transverse module & \\
\hline$n_{1}$ & speed of pinion gear & $\mathrm{rpm}$ \\
\hline$R_{i}$ & input gear radius & $\mathrm{mm}$ \\
\hline$r$ & shaft radius & $\mathrm{m}$ \\
\hline$T_{i}$ & input gear torque & $\mathrm{N} \cdot \mathrm{m}$ \\
\hline$T_{o}$ & output gear torque & $\mathrm{N} \cdot \mathrm{m}$ \\
\hline V & pitch line velocity & $\mathrm{m} / \mathrm{s}$ \\
\hline$Y_{X}$ & size factor for bending strength & \\
\hline$Y_{J}$ & geometry factor for bending strength & \\
\hline$Y_{\beta}$ & lengthwise curvature factor for bending strength, & \\
\hline$\phi$ & gear pressure angle & deg. \\
\hline$\delta$ & gear reference cone angles & deg. \\
\hline$\kappa$ & safety shock factor & \\
\hline$\alpha$ & column action factor & \\
\hline$\tau_{\text {all }}$ & allowable shaft material strength & $\mathrm{MPa}$ \\
\hline$\phi_{\max }$ & torque deformation angle & deg. \\
\hline$\delta_{R}$ & spline tooth root deformation & $\mathrm{mm}$ \\
\hline$\mu$ & Poisson ratio & \\
\hline$\theta$ & load inclination angle & deg. \\
\hline$W$ & tooth width & $\mathrm{mm}$ \\
\hline$h$ & tooth width at the root & $\mathrm{mm}$ \\
\hline$\tau$ & bending stress & $\mathrm{N} / \mathrm{m}^{2}$ \\
\hline
\end{tabular}

